\title{
Yield and Quality of Huitlacoche on Sweet Corn Inoculated with Ustilago maydis
}

M.E. Valverde, P. Fallah Moghaddam', M.S. Zavala-Gallardo', J.K. Pataky', O. Paredes-Lopez, and W.L. Pedersen'

Centro de Investigation y de Estudios Avanzados del Instituto Politecnico National, Unidad Irapuato, Apartado Postal 629, Irapuato, GTO, Mexico

Additional index words. common smut, cuitlacoche, maize mushroom, Ustilago zeae, Zea mays

Abstract. Ear gall development was evaluated after inoculating sweet corn (Zea mays L.) hybrids with Ustilago maydis (DC) Corda by injecting sporidial suspensions into silk channels when silks had emerged $\approx 3$ to $6 \mathrm{~cm}$ from ear shoots. Gall incidence was $\approx 35 \%$ in two inoculation trials. About $0.5 \%$ of the noninoculated control plants was infected. Gall weight increased $\approx 250 \%$ to $500 \%$ between 14 and 21 days after inoculation, reaching a maximum of $\approx 280$ to $600 \mathrm{~g}$. Gall tissue was nearly $100 \%$ black and had lost its spongy integrity 19 to 21 days after inoculation, when mycelial cells formed powdery teliospores. A 1- or 2-day harvest window during which huitlacoche yield and quality were optimized corresponded to the time at which $60 \%$ to $80 \%$ of the gall tissue was black. The optimal huitlacoche harvest time varied among hybrids from 17 to 19 days after inoculation, but we suspect that optimal harvest time varies from $\approx 15$ to 24 days after inoculation, depending on the growth stage at which the host is inoculated and the environmental conditions following inoculation. Differences among sweet corn hybrids in gall incidence, gall size, and coverage of mature galls by husk leaves were observed and could be used to select sweet corn hybrids that are well suited for producing huitlacoche.

Several fungal species are edible (Gray, 1970), but only a few are cultivated on a large scale; e.g., Agaricus bisporus (Lange) Imbach and Lentinus edodes (Berk) Sing. (shiitake). Ustilago maydis galls on corn ears have been harvested from naturally infected fields and eaten in parts of Mexico and Latin America since the time of the Aztecs, who named it cuitlacoche (Kennedy, 1989). Huitlacoche, as it was called by the Spaniards, is sold during the rainy season in the open-air markets of central Mexico. In some years, $>90 \mathrm{Mg}$ is canned by Mexican food processors (Valverde, 1992). Articles about huitlacoche have appeared recently in several popular periodicals in the United States, where it has been marketed as maize mushrooms, Mexican truffles, or maizteca mushrooms. In the United State fresh and frozen huitlacoche has sold for as much as $\$ 20 / \mathrm{kg}$. In spite of the potential value of huitlacoche, there are few reports on cultivating $U$. maydis. Instead, infected ears are gleaned from corn fields, where $U$. maydis causes the disease common smut.

Common smut can cause large economic losses in susceptible corn hybrids. Host resis tance is the only practical control method. Because of the inconsistent results obtained by inoculating plants with $U$. maydis and its genetic diversity, resistance usually is evalu-

Received for publication 14 Sept. 1992. Accepted for publication 4 Mar. 1993. The cost of publishing this paper was defrayed in part by the payment of page charges. Under postal regulations, this paper therefore must be hereby marked advertisement solely to indicate this fact.

'Dept.ofPlant Pathology, Univ. of Illinois, Urbana, IL 61801. ated by the ability of a corn genotype to withstand natural infection in the field (Christensen, 1963). Reliable methods of inoculating corn with several lines of $U$. maydis could improve breeding for resistance to common smut and also could be used to produce huitlacoche.

Inoculating corn plants by injecting them with a sporidial suspension using a hypodermic syringe has been effective in testing the compatibility of haploid sporidial $U$. maydis lines and the virulence of isolates (Christensen, 1963). This method also has been used extensively in many $U$. maydis genetic studies. Although these methods have induced galls successfully, little attention was given to the plant tissues on which the galls form until recently, when several inoculation methods were evaluated for their ability to induce smut galls on corn ears (Pataky, 1990, 1991; Pope and McCarter, 1991, 1992a, 1992b; Thakur et al., 1989; Valverde, 1992; Zimmerman and Pataky, 1992). The incidence of ear galls increased significantly by injecting sporidia or teliospores into silk charnels $\approx 3$ to 4 days after silks emerged. Although relatively labor- intensive compared to other methods, silk channel inoculation has potential for producing commercial huitlacoche crops and screening for disease resistance.

Since huitlacoche usually is gleaned from naturally infected fields, little is known about the optimal harvest time after inoculation. Huitlacoche yield and quality are nearly synonymous with gall enlargement and maturation. Smut galls develop rapidly on sweet corn ears from $\approx 8$ days after midsilk (50\% of plants with silks emerged) until corn harvest, $\approx 19$ to 21 days after midsilk. During this time, galls enlarge and hyphal cells gelatinize to form dark, echinulated teliospores. Mature galls, containing billions of teliospores, can be colonized by species of Aspergillus, Fusaria, Mucor, Penicillin, and other fungi (Christensen, 1963), which render the galls unacceptable as huitlacoche. Additional information on the rate of gall enlargement, teliospore formation, and gall colonization by other organisms would be useful in determining when to harvest huitlacoche crops. This paper reports on preliminary studies to identify the harvest time at which huitlacoche yield and quality are optimized after inoculating sweet corn silks with $U$. maydis sporidia.

Huitlacoche development. Huitlacoche development was followed in a field study at the Univ. of Illinois, Champaign. Four sweet corn hybrids ('Florida Staysweet', 'How Sweet It Is', 'Sweetie 82', and XPH 2688 sh2) were planted on 8 May 1992. Standard production practices were followed, except that insecticides were not applied. The design was a randomized complete block with three replications. Treatments were the four hybrids inoculated with $U$. maydis and sampled on 8 consecutive days beginning 14 days after inoculation. Each main plot consisted of eight subplots. Each subplot included four 3.2-m rows spaced $76 \mathrm{~cm}$ apart with $\approx 10$ plants per row. One subplot from each main plot was

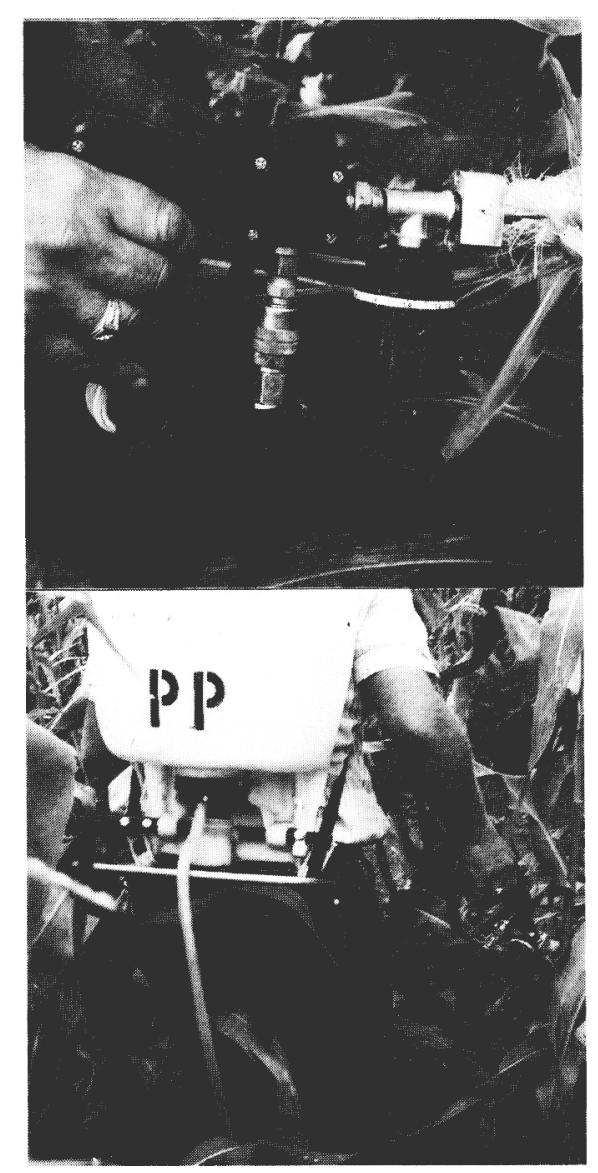

Fig. 1. Sporidial Ustilago maydis suspensions were injected into the silk channels of sweet corn ears with a hand-held spray gun (top) attached to a backpack sprayer containing the inoculum (bottom). Silks had emerged from ear shoots $\approx 3$ to $6 \mathrm{~cm}$. 
sampled on each sampling date. Also, one subplot of each hybrid from a noninoculated replication was harvested each day as a control. The controls were used to compare inoculated and noninoculatedplants; however, since the controls were not randomized within the three replications of inoculated hybrids, they

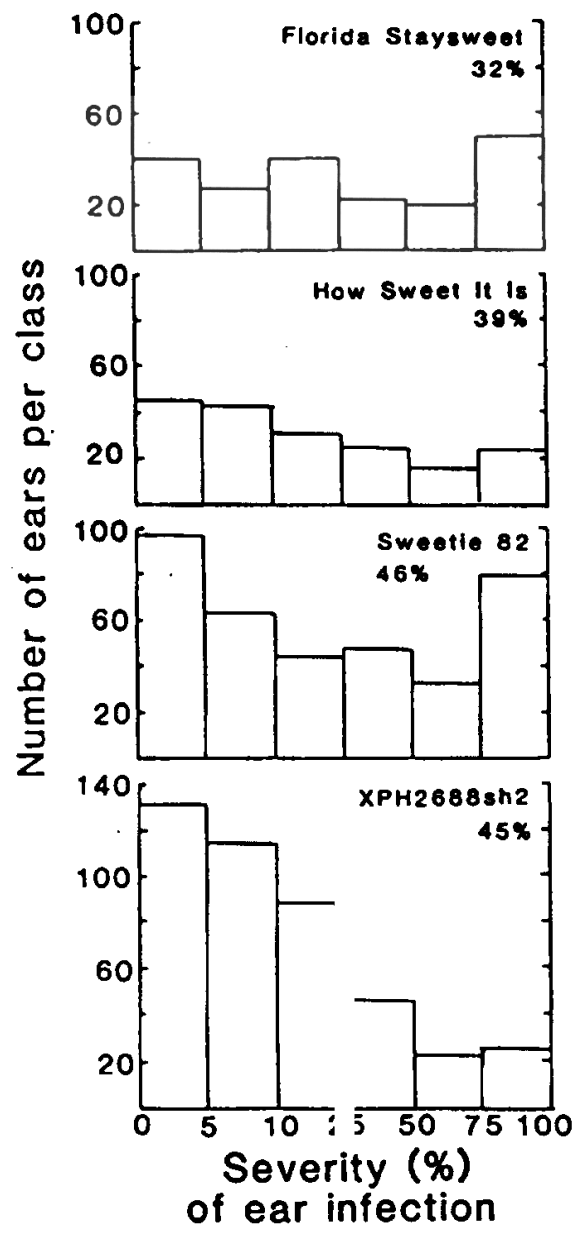

Fig. 2. Infection severity (percentage of kernels infected per ear) on sweet com hybrids 'Florida Staysweet', 'How Sweet It Is', 'Sweetie 82', and XPH 2688 sh2, for which mean incidence of infection was $32 \%$, $39 \%, 46 \%$, and $45 \%$, respectively. were not included in the analysis of variance (ANOVA).

Two monosporidial $U$. maydis lines originally isolated and designated no. 2 and no. 11 by K.J. Leonard [U.S. Dept. of Agriculture-Agricultural Research Service (USDA-ARS), Univ. of Minnesota, St. Paul] were obtained from M.L. Carson (USDA-ARS, North Carolina State Univ., Raleigh) and maintained at $-80 \mathrm{C}$ on a $15 \%$ glycerol solution. The isolates were identified as different mating types in previous studies (Thakur et al., 1989; Pataky, 199 1). To produce inocula, the isolates were cultured on potato-dextrose agar and potatodextrose broth for $\approx 3$ days.

The primary ear shoots of all plants were inoculated on 21 July when silks had emerged $\approx 3$ to $6 \mathrm{~cm}$. Agar and broth cultures were mixed and diluted to produce a suspension of $\approx 5000 \mathrm{sporidia} / \mathrm{ml}$. Eight milliliters of the sporidial suspension was injected down the silk channel with a hand-held spray gun (Meterjet, model 23624; Spraying Systems Co., Wheaton, Ill.) (Fig. 1, top) attached by a hose to a backpack sprayer (Solo, model 425; Grower Equipment Supply, Gainesville, Ill.) containing the inoculum (Fig. 1, bottom).

All primary ears were harvested from one subplot per main plot beginning 14 days after inoculation and continuing daily until 21 days thereafter. Husk leaves were removed and ears were rated for severity of infection, i.e., the percentage of the ear that was covered with galls: $0 \%,>0 \%$ to $5 \%,>5 \%$ to $10 \%,>10 \%$ to $25 \%,>25 \%$ to $50 \%,>50 \%$ to $75 \%,>75 \%$ to $90 \%$, and $>90 \%$. The 10 ears that had the most infection from each main plot were tested further. Ear weight was recorded for each sample and the galls were cut from the cob with an electric knife, weighed, and evaluated (e.g., appearance, firmness, and lack of secondary microbes). Gall weight of a $100 \%$-infected ear was calculated as a weighted mean by dividing the weight of galls cut from the sample by the sum of the proportion of the sample that was infected: gall weight of a $100 \%$-infected ear $=$ gall weight of sample/ $10 \Sigma(i=n)($ severity of infection/100), where $n$ $=$ number of ears in each sample. The percent- age of the gall tissue that was black (i.e., forming teliospores; culinarily desirable) also was estimated from each cut sample. Percentage data were arcsin-transformed before analysis; retransformed data are presented. Hybrids and sampling dates were compared by ANOVA and multiple comparison tests (BLSD, $\mathrm{k}=100$ ).

Hybrid evaluation. We evaluated 350 sweet corn hybrids for susceptibility to $U$. maydis at the Univ. of Illinois (Champaign) South Farm in 1992. The design was a split plot with three replications. Main plots were blocks of 50 or 60 hybrids grouped by endosperm mutation (su, se, or sh2). Subplots were single 16-m rows of hybrids spaced $76 \mathrm{~cm}$ apart with $\approx 70$ seeds planted per row. Naturally occurring common smut was evaluated in two replications that had not been inoculated. All primary ears in one replication were inoculated as described previously. In the inoculated replication, hybrids were evaluated daily from 29 June to 21 July for midsilk growth stage. Plants were inoculated once 2 to 4 days after midsilk on $2,6,9,13,16,20$, or 23 July. Percentage of ears with galls was rated 14 to 21 days after inoculation in the inoculated replication. Other hybrid characteristics that could be important for producing huitlacoche also were noted; e.g., large galls, husk leaves covering mature galls, and microbial contamination of galls. Ears from the inoculated replication were sampled randomly 8 to 22 days after inoculation and evaluated as in the gall development experiment. In the two noninoculated replicates, gall incidence was rated in mid-August.

Huitlacoche production. Injecting sporidia into silk channels successfully produced ear galls. Gall incidence on primary ears of inoculatedplants was $32 \%, 39 \%, 46 \%$, and $45 \%$ for 'Florida Staysweet', 'How Sweet It Is', 'Sweetie 82', and XPH 2688 sh2, respectively (Fig. 2). Only five of 1066 primary ears were infected in the noninoculated replicate.

Infection severity differed among hybrids (Fig. 2). About 70 of 200 infected 'Florida Staysweet' ears $(35 \%)$ and 120 of 380 infected 'Sweetie 82 ' ears $(31 \%)$ had $>50 \%$ of the ear covered with galls. Only 45 of 200 infected
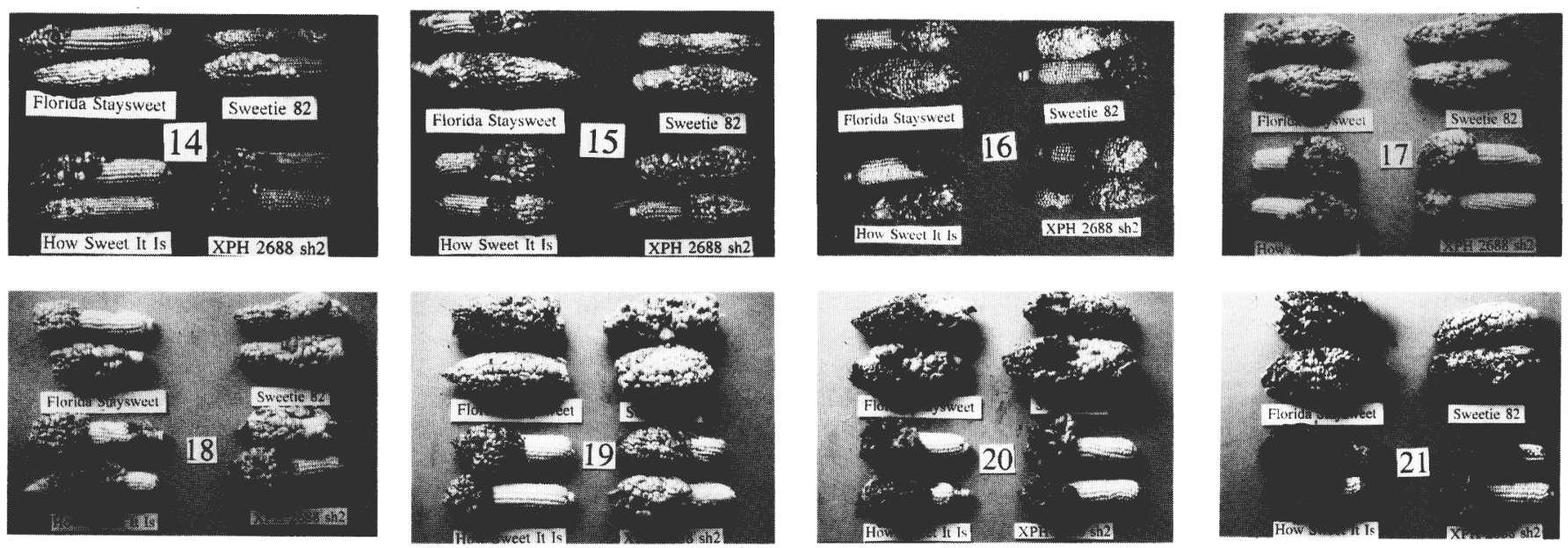

Fig. 3. Ustilago maydis gall development on ears of sweet corn hybrids 'Florida Staysweet', How Sweet It Is', 'Sweetie 82', and XPH 2688 sh2 14 to 21 days after inoculation. 
'How Sweet It Is' ears (23\%) and 45 of 435 infected XPH 2688 sh2 ears (10\%) were more than half covered with galls. Galls formed only on the tips ( $\approx 10 \%$ of the ear) of about half of the infected 'How Sweet It Is' and XPH $2688 \operatorname{sh} 2$ ears, respectively (Figs. 2 and 3 ).

Gall weight increased $\approx 250 \%$ to $500 \%$ between 14 and 21 days after inoculation (Fig. 4). Gall weight of $100 \%$-infected XPH 2688 sh2 ears increased nearly $250 \%$ (230 to $600 \mathrm{~g}$ ) and that of' Sweetie 82' ears increased $500 \%$ (70 to $350 \mathrm{~g}$ ) during the 8-day sampling period. 'How Sweet It Is' and XPH 2688 sh2 galls were within $90 \%$ of their maximum weight 17 days after inoculation. For these hybrids, gall weight did not differ significantly between 17 and 21 days after inoculation. 'Florida Staysweet' and 'Sweetie 82' galls weighed $\approx 90 \%$ of their maximum 18 and 19 days after inoculation, respectively, and gall weight did not differ significantly between 18 and 21 days after inoculation.

The percentage of black gall tissue ranged from $7 \%$ to $20 \% 14$ days after inoculation and increased to $98 \%$ to $100 \%$ by 21 days after inoculation (Fig. 4). The rate at which galls became black was similar for the four hybrids, although 'Florida Staysweet' and 'Sweetie 82 ' were $\approx 1$ and 2 days later than 'How Sweet It Is' and XPH 2688 sh2. About $80 \%$ of 'How Sweet It Is' and XPH $2688 s h 2$ gall tissue was black 17 days after inoculation, when galls first reached $90 \%$ of their maximum weight the percentage of black gall tissue did not differ significantly between 18 and 21 days after inoculation. About $70 \%$ of 'Florida Staysweet' and 'Sweetie 82' gall tissue was black 18 and 19 days after inoculation, respectively, when galls first reached $90 \%$ of their maximum weight 20 days after inoculation,

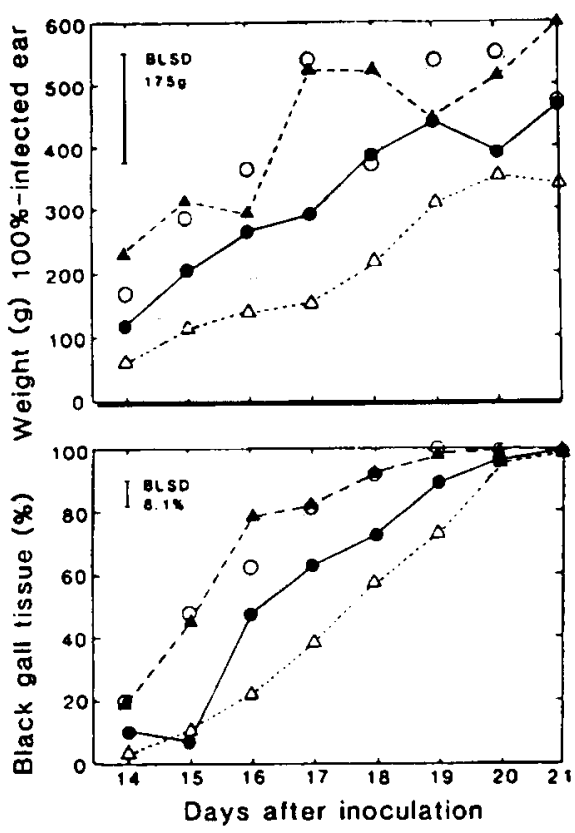

Fig. 4. Gall weight (g) from $100 \%$-infected ears (see text for calculation) of 'Florida Staysweet' (O) 'How Sweet It Is' (O), 'Sweetie 82' ( $\Delta$ ), and $\mathrm{XPH} 2688 \operatorname{sh} 2(\boldsymbol{\Delta})$, and percentage of gall tissue that was black 14 to 21 days after inoculation. the percentage of black gall tissue did not differ significantly from $100 \%$.

Initially, galls were white and very dense. As they developed, galls were covered by a silvery white membrane (peridium) and had a spongy or fleshy texture, similar to that of cultivated mushrooms. At 14 days after inoculation, gall tissue was either immature, white, and dense or beginning to enlarge, had a silvery appearance, and the peridium was intact (Fig. 3). As they approached maturity, galls turned black and lost their integrity as the peridia ruptured and spongy tissue turned to powdery teliospores. Gall tissue began to lose integrity, peridia ruptured, and microbial contamination was observed 18 days after inoculation on 'How Sweet It Is' and XPH 2688 sh2 and 20 days after inoculation on 'Florida Staysweet' and 'Sweetie 82' (Fig. 3). Gall quality for huitlacoche (spongy tissue, intact peridia, lack of microbial contamination) coincided with our ratings of $50 \%$ to $70 \%$ black gall tissue.

Hybrid evaluation. Galls formed on ears of $\approx 34 \%$ (5593 of 16,284$)$ of the inoculated plants. In the two noninoculated replications, ear galls formed on $\approx 0.5 \%$ (174 of 32,533) of the plants as a result of natural infection. Gall incidence varied among hybrids from $0 \%$ to $96 \%$ in the inoculated replication, and from $0 \%$ to $20 \%$ in the noninoculated replications. None of the 350 hybrids had a higher incidence of ear galls in the noninoculated than in the inoculated replications.

Gall incidence was $260 \%$ for $\approx 10 \%$ of the hybrids evaluated (Table 1). Thirty-five hybrids with $>34 \%$ incidence also had husk leaves that covered mature galls (Table 2, Fig. 5). Twenty-one hybrids with at least $34 \%$ gall incidence had particularly large galls (Table 2, Fig. 5). Gall weight of $100 \%$-infected ears ranged from $\approx 280$ to $550 \mathrm{~g}$ among the hybrids that were sampled randomly 18 to 22 days after inoculation. The percentage of black gall tissue and the rate of gall enlargement seemed to follow the same pattern that was observed in the huitlacoche development experiment (Fig. 6 ). Infected kernels were recognized easily 8 or 11 days after inoculation, although galls were small and teliospores had not formed. Galls had enlarged but were $<50 \%$ black 15 days after inoculation. Galls were almost fully enlarged and $\approx 70 \%$ to $90 \%$ black 18 days after inoculation. Galls usually were too mature to be acceptable for huitlacoche and secondary microbe growth was frequent 22 days after inoculation.

A 1- or 2-day harvest window during which huitlacoche yield and quality were optimized in this preliminary study seemed to correspond to the time at which $60 \%$ to $80 \%$ of the gall tissue was black. Beyond this optimal stage, gall quality deteriorated rapidly, even though the galls continued to enlarge slightly. This deterioration was due to the loss of gall integrity (i.e., fleshy, spongy quality) as gall tissue became mostly teliospores, peridia ruptured, and microbes frequently contaminated galls not covered by husk leaves.

When measured as days after inoculation, the harvest window differed slightly among
Table 1 . Sweet corn hybrids with $>60 \%$ of the ears infected with Ustilago maydis after silks were inoculated with a sporidial suspension.

Hybrid

Infected ears

Jasper

Hypak

MM1-131

Revere

HMX $0369 \mathrm{~S}$

Sch 4041

Sugar Buns

Sch 27556

Sch 5009

XPH 3039 BC sh2

Paragon

XPH 3047

XPH $3081 s h 2$

Sweet Tennessee

Seneca RXY 6502

Sch 6075

Sch 27556

Sch 20689

Casper

MM1-275

Butter Sweet

Classic Touch

Earlivee II

Sch 30138

Sch 4703

Sunex 2642

$(\%)$
96

90

85

85

81

81

79

77

76

76

75

75

75

74

72

72

72

71

71

69

69

69

69

67

Green Giant Code 17

SW-450B

Sch 14272

Camelot

Butter Vee

Sch 23755

SW-235B

XPH 3036 BC sh2

Eliminator

GH 2757

67

66

66

65

63

61

61

60

hybrids. Seventeen days after inoculation seemed to be the optimal harvest time for 'How Sweet It Is' and XPH 2688 sh2 galls. Eighteen and nineteen days after inoculation seemed to be optimal for 'Florida Staysweet' and 'Sweetie 82' galls, respectively. At the optimal harvest time, gall weight was nearly maximum, $\approx 70 \%$ of the gall tissue was black, secondary microbes were not apparent on gall tissue, and galls were fleshy and intact.

Apparently, U. maydis maturation is related to host maturation. 'How Sweet It Is' and XPH $2688 \operatorname{sh} 2$ matured $\approx 2$ or 3 days earlier than 'Florida Staysweet' and 'Sweetie 82', as noted by earlier pollen shed, midsilk stage, and fresh-market corn harvest.Ustilago maydis galls also matured 1 or 2 days sooner on the earlier-maturing hybrids. Since the rate of sweet corn maturation is associated with an accumulation of heat units and since gall maturation may be affected by the host's maturation, heat units may affect huitlacoche harvest time. The 1992 growing season in central Illinois was unusually cool and may not be reflective of warmer environments. Therefore, days after inoculation can be used only as a general guide to determine when gall tissue is $70 \%$ black and gall weight is maximum. When huitlacoche was produced commercially on the hybrid 'Silver' Queen' in Lancaster County, Pa., in 1992, the optimal harvest time 
Table 2. Sweet corn hybrids with $\leq 34 \%$ infected ears and large ear galls (L), or husk leaves $(\mathrm{H})$ covering ear galls after silks were inoculated with Ustilago maydis.

\begin{tabular}{|c|c|}
\hline Hybrid & $\begin{array}{c}\text { Infected ears } \\
(\%)\end{array}$ \\
\hline$\overline{M M 1-131}$ & $85 \mathrm{~L}$ \\
\hline Revere & $85 \mathrm{H}$ \\
\hline HMX $0369 \mathrm{~S}$ & $81 \mathrm{H}$ \\
\hline Sch 5009 & $76 \mathrm{H}$ \\
\hline XРH 3047 & $75 \mathrm{~L}$ \\
\hline Sch 6075 & $72 \mathrm{H}$ \\
\hline Sch 20689 & $72 \mathrm{H}$ \\
\hline Butter Sweet & $69 \mathrm{~L}$ \\
\hline Green Giant Code 17 & $66 \mathrm{~L}$ \\
\hline SW-450 B & $66 \mathrm{H}$ \\
\hline SW-235 B & $61 \mathrm{~L}$ \\
\hline XPH 3036 BC sh2 & $61 \mathrm{H}$ \\
\hline Eliminator & $60 \mathrm{H}, \mathrm{L}$ \\
\hline MM1-0017 & $59 \mathrm{H}$ \\
\hline MM1-0076 & $57 \mathrm{H}$ \\
\hline GH 0035 & $56 \mathrm{H}, \mathrm{L}$ \\
\hline Sch 11083 & $56 \mathrm{~L}$ \\
\hline Clockwork F-1 & $55 \mathrm{H}, \mathrm{L}$ \\
\hline XPH 3064 sh2 & $54 \mathrm{H}, \mathrm{L}$ \\
\hline Starbrite & $53 \mathrm{H}$ \\
\hline Bi-Honey Delight & $52 \mathrm{H}$ \\
\hline Flavor Queen & $51 \mathrm{H}$ \\
\hline HMX $8386 \mathrm{~S}$ & $51 \mathrm{~L}$ \\
\hline Sunex 2640 & $50 \mathrm{~L}$ \\
\hline Summer Flavor $79 \mathrm{BC}$ & $49 \mathrm{H}$ \\
\hline Sweet Belle & $49 \mathrm{H}$ \\
\hline Sch 20777 & $46 \mathrm{H}$ \\
\hline MM1-0168 & $45 \mathrm{H}$ \\
\hline MM1-0193 & $45 \mathrm{H}, \mathrm{L}$ \\
\hline Natural Sweet 9000 & $45 \mathrm{~L}$ \\
\hline Norgold & $45 \mathrm{~L}$ \\
\hline Bolero & $42 \mathrm{H}$ \\
\hline Sch 81615 & $42 \mathrm{H}$ \\
\hline Sch 96716 & $42 \mathrm{H}, \mathrm{L}$ \\
\hline Champ & $40 \mathrm{H}$ \\
\hline Ivanhoe & $40 \mathrm{~L}$ \\
\hline Domino & $39 \mathrm{H}, \mathrm{L}$ \\
\hline Springsweet & $38 \mathrm{H}, \mathrm{L}$ \\
\hline Stylepak & $38 \mathrm{H}$ \\
\hline Xtra Sweet 82 & $38 \mathrm{~L}$ \\
\hline GSS 3492 & $37 \mathrm{H}$ \\
\hline Calico Belle & $36 \mathrm{H}, \mathrm{L}$ \\
\hline MM1-0168 & $36 \mathrm{H}$ \\
\hline XРH 3019 BC sh2 & $35 \mathrm{H}$ \\
\hline Bodacious & $34 \mathrm{H}$ \\
\hline Lancelot & $34 \mathrm{H}$ \\
\hline
\end{tabular}

was 21 or 22 days after inoculation (C. Arnold, personal communication). The Lancaster environment may have slowed $U$. maydis development or ears may have been inoculated a few days earlier than in our experiments.

Husk leaves' covering mature galls seemed to be an attribute of some sweet corn hybrids that would be highly beneficial in huitlacoche production. For many hybrids, galls had enlarged through the husk leaves by 18 or 19 days after inoculation. We observed that exposed galls were contaminated by microbes more frequently than nonexposed galls. Exposed galls also were damaged considerably when harvested by hand.

Several sweet corn hybrids seemed to be useful for producing huitlacoche because of a high incidence of infected ears, large galls, and good husk coverage. Other types of corn also should be considered for huitlacoche. Susceptible floury maize with large ears may

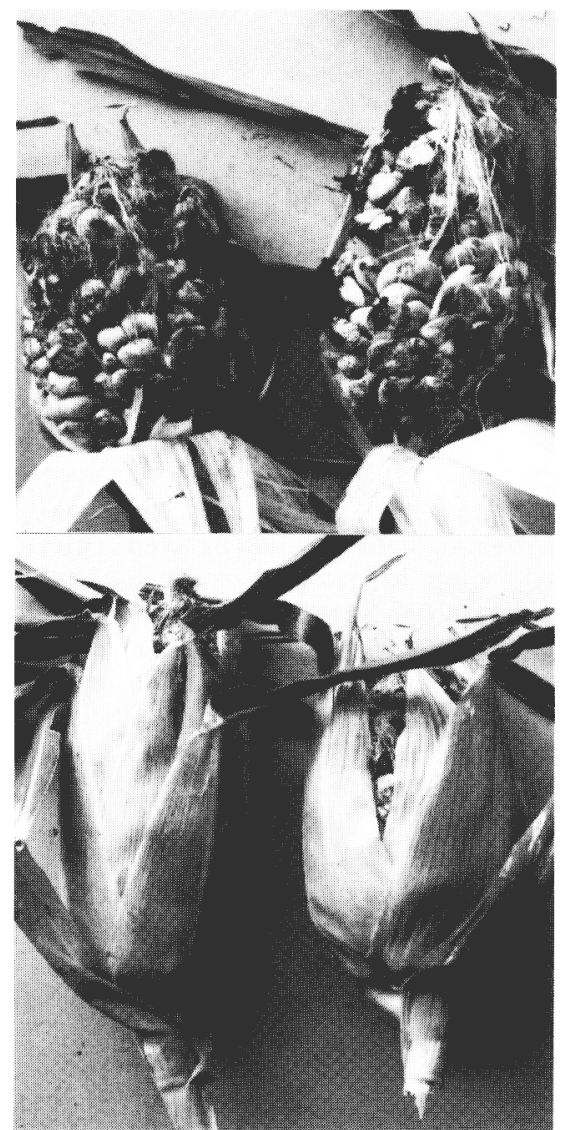

Fig. 5. Large ear galls (top) and galls covered by husk leaves (bottom) on sweet corn hybrids randomly selected 18 to 22 days after inoculation.
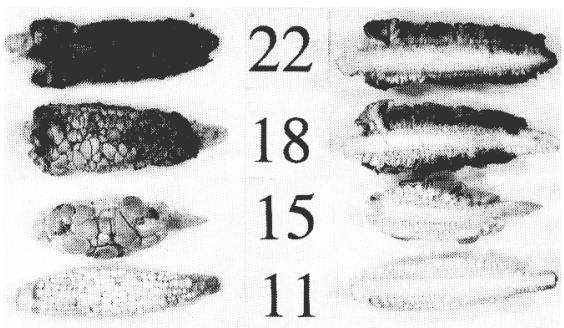

Fig. 6. Ustilago maydis gall development on ears of randomly selected sweet corn hybrids 11,15 , 18 , and 22 days after inoculation.

be especially good. Although we did not record specific data, we observed that gall weight was related to ear size. Also, silk and pericarp traits may be evaluated in view of recent observations made during electron microscopic examinations of the initial stages of $U$. maydis infection of stigmas and ovaries (Snetselaar and Mires, 1992).

Additional studies on $U$. maydis inoculation method and gall harvest time could improve huitlacoche production. Our inoculation method and the combination of sporidial isolates no. 2 and no. 11 consistently have resulted in a lower incidence and severity of ear galls than the techniques used by Pope and McCarter (1991, 1992a, 1992b). They reported a $>90 \%$ incidence of ear galls using cob and tip injection methods with specific pair-wise com- binations of compatible sporidial lines, for which a patent application has been made. A more precise evaluation of microbial colonization of mature galls would be prudent, especially in Mexico, where corn ears are infected by ergot (Claviceps gigantea) (Fucikovsky and Moreno, 1971; Fuentes et al., 1964). Ergot-infested corn can be fatal when eaten by humans and animals (Fuentes et al., 1964).

Additional research is needed to determine if silk channel inoculation will be useful in evaluating the resistance of sweet corn germplasm to $U$. maydis. Four important questions must be asked: 1) can the method be used efficiently when differences in maturity occur in large germplasm collections? 2) Does the technique mask certain resistance mechanisms that are important in natural infection (Kyle, 1929)? 3) Is the technique reliable enough to identify resistant genotypes in segregating populations? 4) Does specificity among hostresistance genes and pathogen-virulence genes require using a large collection of $U$. maydis isolates?

\section{Literature Cited}

Christensen, J.J. 1963. Corn smut caused by Ustilago maydis. Amer. Phytopathol. Soc. Monogr. 2.

Fucikovsky, L. and M. Moreno. 1971. Distribution of Claviceps gigantea and its percent attack on two lines of corn in the state of Mexico, Mexico. Plant Dis. Rpt. 55:231-233.

Fuentes, S.F., M. de Lourdes de la Isla, A.J. Ullstrup, and A.E. Rodruiquez. 1964. Claviceps gigantea, a new pathogen of maize in Mexico. Phytopathology 54:379-381

Gray, W.D. 1970. The use of fungi in food processing. CRC Critical Rev. Food Tech. p. 225-240.

Kennedy, D. 1989. The art of Mexican cooking. Bantam, New York.

Kyle, C.H. 1929. Relation of husk covering to smut of corn ears. U.S. Dept. Agr. Tech. Bul. 120.

Pataky, J.K. 1990. Production of huitlacoche, Ustilago maydis. Phytopathology 80:1044.

Pataky, J.K. 1991. Production of cuitlacoche [Ustilago maydis (DC) Corda] on sweet corn. HortScience 26:1374-1377.

Pope, D.D. and S.M. McCarter. 1991. The effect of inoculation method on disease incidence and severity of the corn smut caused by Ustilago maydis. Phytopathology 81:814.

Pope, D.D. and S.M. McCarter. 1992a. Evaluation of inoculation methods for inducing common smut on corn ears. Phytopathology 82:950-955.

Pope, D.D. and S.M. McCarter. 1992b. Smut incidence and severity after inoculating developing corn ears with Ustilago maydis using different methods. Phytopathology 82:500.

Snetselaar, K.M. and C.W. Mires. 1992. Infection of maize stigmas by the smut fungus, Ustilago maydis. Inoculum 43:50.

Thakur, R. P., K.J. Leonard, and J.K. Pataky. 1989. Smut gall development in adult corn plants inoculated with Ustilago maydis. Plant Dis. $73: 921-925$.

Valverde, M.E. 1992. Estudios sobre la infecion del huitlacoche (Ustilago maydis) y sus caracteristicas alimentarias. MS Thesis, Centro de Investigation y de Estudios Avanzados del Instituto Politecnico National, Irapuato, Mexico.

Zimmerman, S.A. and J.K. Pataky. 1992. Inoculation techniques to produce galls of common smut on ears of sweet corn. Phytopathology 82:995. 